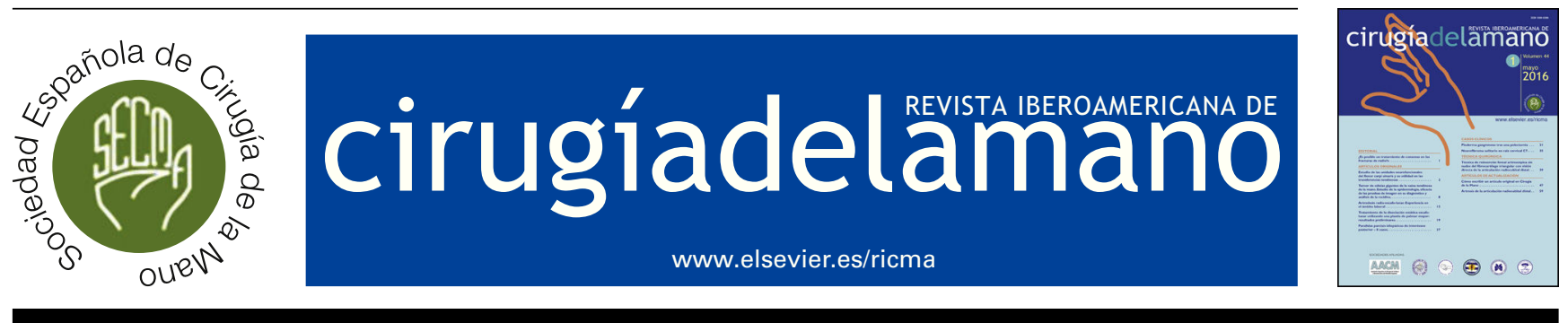

\title{
Abrirse al mundo: una necesidad ineludible
}

\section{Opening up the world: An inevitable necessity}

\begin{abstract}
«¿A quién se le ocurre salir fuera de nuestras fronteras para aprender más? ¿Qué le pueden enseñar los yanquis que no pueda aprender aquí? ¡Y encima en inglés!» No sé si fue exactamente así, pero es probable que Jaime Planas Guasch tuviera que aguantar a menudo este tipo de comentarios cuando, en 1947, decidió marchar a los Estados Unidos para ampliar sus conocimientos como cirujano plástico. No debió de ser fácil plantearse esa posibilidad en unos momentos en los que el bloqueo internacional teñía los ambientes universitarios de xenofobia radical. Pero Jaime fue siempre un librepensador, y lo hizo. Poco después de defender su tesis doctoral sobre las amputaciones en cirugía de urgencias, le llegó la carta que estaba esperando: la Fundación del Amo de Los Ángeles le acababa de conceder una beca para una estancia de 12 meses en los Estados Unidos. El objetivo: aprender las nuevas técnicas quirúrgicas que permitían reconstruir las manos traumatizadas. Conocía, por su tesis, cómo y cuándo amputar. Ahora le ofrecían aprender a salvar la extremidad, y no dudó ni un segundo: aceptaría esa propuesta.
\end{abstract}

Para muchos, California no era más que el escenario de «Fuerte apache», de John Ford. Para el joven doctor era el lugar donde Sterling Bunnell y su equipo estaban forjando las bases de la cirugía de la mano moderna. Tenía 32 años, soltero y sin compromiso. Sobreponiéndose a toda clase de dificultades, y tras visitar diversos hospitales en Chicago, Saint Louis, New Orleans y Los Ángeles, pudo al fin ser admitido como visiting fellow en el Saint Francis Memorial Hospital, de San Francisco. Sabía que trabajar allí era una oportunidad única, y la aprovechó al máximo. Destacando pronto por su entusiasmo, generosidad y capacidad de trabajo, no es extraño que el Dr. Sterling Bunnell se fijara en aquel joven, y le pidiera que se encargara de la traducción al español de la segunda edición de su libro Surgery of the hand. Y no se equivocó. En 1951 el libro estaba ya en todas las librerías especializadas iberoamericanas. ¿De quién fue el mérito? ¿De la Fundación Jaime del Amo que pagó su estancia?, ¿del Dr. Bunnell que creyó en él?, ¿o de la generosidad de espíritu y amplitud de miras de ese joven trabajador? ¡Qué más da! Lo importante es que, al abrirse sin complejos al mundo, Jaime Planas logró que la cirugía de la mano moderna entrara en nuestros hospitales. Aquel libro fue, sin duda, uno de los mejores regalos que podía hacer a los cirujanos hispanoparlantes el que, años más tarde, en 1969, sería uno de los fundadores de la Sociedad Española de Cirugía de la Mano (SECMA). Entusiasmo, generosidad y trabajo. Esas son las palabras clave de esa historia.

Y que conste que, aun siendo ejemplar, esa no es la única historia que podía haber contado para justificar por qué es tan importante abrirse al mundo. Aparte del Dr. Planas, la cirugía de la mano en España tuvo la suerte de contar con muchos otros pioneros (Enríquez de Salamanca, Cañadell, Palazzi Duarte, Quintana), y es gracias a ellos que nunca vivió de espaldas a lo que ocurría fuera de nuestras fronteras. Todo lo contrario, nunca hubo un congreso de la SECMA en que no se invitara, con todos los honores, a los más prominentes cirujanos extranjeros (Pulvertaft, Tubiana, Matev, Vainio, Souquet. ..). Seguro que no fue fácil, seguro que hubo quejas, seguro que muchos no comprendieron por qué tanto empeño, pero valió la pena, y debemos agradecérselo.

Afortunadamente, ya no es necesario estimular a nuestros jóvenes residentes a que se preparen para completar sus estudios en el extranjero. En España se puede acceder a una excelente formación en cirugía de la mano, sin necesidad de salir del país. ¿Quiere esto decir que podemos ya prescindir de lo que ocurre más allá de nuestras fronteras? ¿Podemos rehusar a colaborar en las instituciones internacionales? La respuesta es un categórico ¡no!

Dejémonos de matices estériles y reconozcámoslo: nuestro mundo es global. La globalización no es un fenómeno transitorio al que podamos renunciar. La globalización está ahí, y no hay caminos alternativos que la obvien. Como los duty-free shops que nos obligan a cruzar para llegar a las puertas de embarque de los aeropuertos, no podemos vivir a 
espaldas de la globalización de nuestro planeta. Negarnos a ello sería tan absurdo como esconderse detrás de una muralla que impidiera al resto del mundo saber quiénes somos o qué nos ocurre. Podríamos hacerlo, pero no debemos. ¿Por qué?

En primer lugar, porque somos agradecidos. Al principio, en los años 40 y 50 , éramos deudores netos en nuestra relación con los que desarrollaron la cirugía de la mano moderna. Ahora somos netos contribuyentes, y debemos contribuir en la medida que seamos capaces de hacerlo. Si hemos crecido lo suficiente como para que algunos vean en nosotros lo que en su tiempo fue California para el Dr. Planas, tenemos la obligación de aceptar ese reto. Como dice el refranero: «es de mal nacido no ser agradecido». Pues bien, la mejor manera de agradecer, a los que nos ayudaron a crecer individual y colectivamente, es colaborar con el mismo entusiasmo, generosidad y trabajo a que los países que vienen detrás - menos favorecidos, con menos recursospuedan acceder a lo que nosotros, ahora, tenemos fácilmente. Esta, y no otra, debe ser la primera motivación para ofrecernos a colaborar con aquellas entidades supranacionales que velan para que las buenas prácticas en cirugía de la mano se extiendan a todos los países.

En segundo lugar, debemos colaborar porque nos interesa hacerlo. Siempre es lo mismo. Aquí y en todas partes. Si en una institución sin ánimo de lucro, como pueda ser la Federación Europea de Sociedades de Cirugía de la Mano (FESSH) o la Federación de Sociedades de Cirugía de la Mano (IFSSH), te piden que colabores, y si a esa petición respondes con entusiasmo, generosidad y dedicación, cuenta con que en poco tiempo te pedirán más. Si trabajas bien, inevitablemente tendrás que aceptar nuevas responsabilidades. Si encima eres dialogante, resolutivo, y sabes hacerlo sin crearte enemigos, no lo dudes, con el tiempo te encontrarás allí arriba, donde se toman las decisiones. Colaborar significa tener la oportunidad de influir en que esas decisiones te sean beneficiosas. Como sabes muy bien, nada se da a cambio de nada, pero no esperes nada si no estás presente en el momento del reparto. Nos conviene pues colaborar, por nuestro propio interés. Sin este espíritu, España nunca hubiera podido llegar a posicionar unos de sus miembros en las cúpulas directivas de la FESSH o de la IFSSH, ni organizar dos de sus congresos.

En tercer lugar, porque es interesante. Colaborar con colegas extranjeros a quienes te une un objetivo común es siempre instructivo, y hasta puede llegar a ser apasionante. Te da la ocasión de viajar a lugares insospechados, a conocer tradiciones, a disfrutar de los beneficios de las muchas amistades que no hubieras tenido si no fuera por tu involucración con las actividades de la institución. Y por supuesto, tendrás el reconocimiento a tu trabajo, que no es poco, tal y como están las cosas.

En resumen, abrirse al mundo: una necesidad ineludible, si bien interesante y provechosa para el país y para uno mismo. No lo dejes para mañana.

M. Garcia-Elias

Federación de Sociedades de Cirugía de la Mano (IFSSH) Sociedad Española de Cirugía de la Mano (SECMA) Federación Europea de Sociedades de Cirugía de la Mano

(FESSH)

Correos electrónicos: garciaelias@institut-kaplan.com, marc@garcia-elias.cat 